Article

\title{
Ag Nanoislands Modified Carbon Fiber Nanostructure: A Versatile and Ultrasensitive Surface-Enhanced Raman Scattering Platform for Antiepileptic Drug Detection
}

\author{
Guochao Shi ${ }^{1}$, Xue Han ${ }^{2}$, Jungai Gu ${ }^{1}$, Wenzhi Yuan ${ }^{1}$, Kuihua Li ${ }^{1, *}$, Liyong Wang ${ }^{3, *(D)}$, Wei Han ${ }^{4}$ and \\ Jianjun $\mathrm{Gu}^{4}$ \\ 1 Department of Biomedical Engineering, Chengde Medical University, Chengde 067000, China; \\ 18232240230@163.com (G.S.); jungai@126.com (J.G.); yuanwenzhiyyds@163.com (W.Y.) \\ 2 Department of Neurology, Affiliated Hospital of Chengde Medical University, Chengde 067000, China; \\ afcdmuhanxue@163.com \\ 3 School of Energy and Power Engineering, North University of China, Taiyuan 030051, China \\ 4 College of Physics and Electronic Engineering, Hebei Normal University for Nationalities, \\ Chengde 067000, China; hwly2006@163.com (W.H.); jjungu@126.com (J.G.) \\ * Correspondence: likuihua@cdmc.edu.cn (K.L.); nucc@nuc.edu.cn (L.W.)
}

Citation: Shi, G.; Han, X.; Gu, J.; Yuan, W.; Li, K.; Wang, L.; Han, W.; $\mathrm{Gu}, \mathrm{J}$. Ag Nanoislands Modified Carbon Fiber Nanostructure: A Versatile and Ultrasensitive Surface-Enhanced Raman Scattering Platform for Antiepileptic Drug Detection. Coatings 2022, 12, 4. https://doi.org/10.3390/ coatings12010004

Academic Editor: Michelina Catauro

Received: 2 December 2021

Accepted: 18 December 2021

Published: 21 December 2021

Publisher's Note: MDPI stays neutral with regard to jurisdictional claims in published maps and institutional affiliations.

Copyright: (C) 2021 by the authors. Licensee MDPI, Basel, Switzerland. This article is an open access article distributed under the terms and conditions of the Creative Commons Attribution (CC BY) license (https:// creativecommons.org/licenses/by/ $4.0 /)$.

\begin{abstract}
A high-efficiency surface-enhanced Raman scattering (SERS) detection method with ultrahigh sensitivity has been widely applied in drug component detection to optimize the product quality verification standards. Herein, a controllable strategy of sputtering Ag nanoislands on carbon fiber (C-fiber) via magnetron sputtering technology was proposed to fabricate a versatile Ag-C-fiber SERS active substrate. A wide range of multi-level electromagnetic enhancement "hot spots" distributed on Ag-C-fiber nanostructures can efficiently amplify Raman signals and the experimental enhancement factor $(E E F)$ value was $3.871 \times 10^{6}$. Furthermore, substantial "hot spots" of large-scale distribution guaranteed the superior reproducibility of Raman signal with relative standard deviation (RSD) values less than $12.97 \%$. Limit of detection (LOD) results indicated that when crystal violet $(\mathrm{CV})$ is employed as probe molecule, the LOD was located at $1 \times 10^{-13} \mathrm{M}$. By virtue of ultra-sensitivity and good flexibility of the Ag-C-fiber nanotemplate, Raman signals of two kinds of antiepileptic drugs called levetiracetam and sodium valproate were successfully obtained using an SERS-based spectral method. The Ag-C-fiber SERS detection platform demonstrated a good linear response $\left(\mathrm{R}^{2}=0.97486\right)$ in sensing sodium valproate concentrations in the range of $1 \times 10^{3} \mathrm{ng} / \mu \mathrm{L}^{-1}-1 \mathrm{ng} / \mu \mathrm{L}$. We believe that this reliable strategy has potential application for trace detection and rapid screening of antiepileptic drugs in the clinic.
\end{abstract}

Keywords: surface-enhanced Raman scattering; carbon fiber; Ag nanoisland; antiepileptic drug

\section{Introduction}

As a universal spectral technology with the advantages of high sensitivity [1] and nondestructive detection, surface enhanced Raman scattering (SERS) has a very important application prospect in the fields of analytical chemistry [2], biomedical sensing [3], food safety detection [4] and ultra-trace detection of toxic pollutants [5]. In the past 40 years, people have made great efforts in understanding the origin of the SERS effect and creating more desirable SERS substrates, which have made continuous progress in theory and experiment. Although the enhancement mechanism of the SERS effect is still controversial, there are two widely accepted enhancement mechanisms: electromagnetic enhancement (EM) mechanism and chemical enhancement (CM) mechanism [6]. When incident light interacts with metal nanoparticles, the conduction band electrons will oscillate collectively under the excitation of an alternating electromagnetic field. If the frequency of incident light is the same as the natural frequency of surface electron oscillation, surface plasmon resonance (SPR) effect will occur [7]. The SPR effect generates a locally enhanced electromagnetic 
field around the nanoparticles. Therefore, surface plasmon resonance is considered to be the main cause of the EM mechanism [8]. The CM mechanism usually originates from the change of molecular polarizability [9]. When molecules are adsorbed on the rough metal surface, there is a strong chemical interaction between molecules and noble metal, therefore, new charge transfer excited states will be generated. When the excitation energy matches the energy of the charge transfer excited state, metal-molecule or molecule-metal charge transfer transition resonance will occur, resulting in the enhancement of SERS signal $[10,11]$. In the SERS enhancement process, the EM and CM mechanisms are not mutually exclusive. As the two mechanisms play a role together, it is difficult to strictly distinguish them. It is generally considered that the EM $\left(10^{4}-10^{12}\right)$ is far greater than the CM $\left(10^{1}-10^{2}\right)$ [12].

The emergence of a large number of novel and multifunctional SERS platforms not only make people have a deeper understanding of the SERS fundamental mechanism, but also provide optimized models/processes for the application of SERS technology [13]. Researches have shown that concave noble metal nanocrystals with sharp edges usually show high-density "hot spots" around their sharpened regions, thus realizing huge electromagnetic field enhancement [14,15]. Lin's group synthesized various geometries of $\mathrm{Au}$ nanocrystals with sharp tips by Ag underpotential deposition-dominated growth approach. The monolayer nanofilms of Au nanocrystals mentioned above were then fabricated by using the liquid/liquid interface self-assembly method. Electromagnetic field simulation results showed that concave Au nanostars show the largest EM field enhancement, and the strong electromagnetic field enhancement was located near the corners and edges of nanocrystals, which provided a "hot spot" region for SERS of single nanocrystals [16]. In current research reports, the SERS substrates modified with graphene or graphene oxide can introduce additional CM to the substrate [17-19]. Yang's research team used the selfassembly method to embed a layer of graphene oxide between Ag nanoparticles and Au nanoparticles. Research results indicated that the charge transfer mode between graphene oxide and probe molecules led to CM enhancement, which enhanced the Raman signal of SERS substrate by 10-100 times [20]. In the same year, the research group modified graphene oxide on the surface of Ag-cicada wing substrate to construct graphene oxideAg-cicada wing hybrid nanostructure. Compared with the Ag-cicada wing unmodified graphene oxide substrate, the difference of EM was very small because graphene oxide mainly enhanced the Raman signal through $\mathrm{CM}$, and $\mathrm{CM}$ had little effect on the electromagnetic field. Although the effect of CM was not prominent, it had a significant effect on improving the activity of SERS substrates [21].

A rapidly developing branch in the field of SERS is the use of carbon-based nanomaterials as substrate materials, such as carbon nanotubes [22,23], carbon dots [24], grapheneenhanced Raman scattering (GERS) $[25,26]$ and so on. Carbon-based materials have excellent adsorption properties and chemical stability. They can be used as supporting templates for SERS substrates and can be compounded with other noble metal nanomaterials to form composite SERS substrates. The enhanced mechanisms of carbon-based SERS substrates include two parts: the CM mechanism of carbon-based nanomaterials and the EM enhancement mechanism dominated by noble metal materials. Meanwhile, as SERS substrates, noble metal materials are prone to photocatalysis and photodegradation of probe molecules under laser induction; fortunately, carbon-based materials can overcome this problem [27]. However, the mass production of carbon-based SERS substrate material with high specific surface area has always puzzled researchers [28]. For example, due to the special nanomorphology on the surface of carbon nanotubes, its specific surface area was as high as $1000 \mathrm{~m}^{2} / \mathrm{g}$ [29]. Although the large Raman cross section of carbon nanotubes made it a promising Raman probe for biomedical sensing, its preparation process was complex, the morphology was uncontrollable, and it cannot be mass produced. These shortcomings further limited the application of carbon-based nanomaterials in SERS field.

In this work, the commercial carbon fiber was applied as SERS template material. The spun fiber was firstly oxidized, then they were carbonized to obtain the C-fibers. However, these sporadic C-fibers were fragile and hard to apply to the preparation of SERS substrate. 
Therefore, a knitting machine was used to spin C-fibers into C-fiber fabrics. The surface of Cfiber fabrics was then decorated with Ag nanoislands by magnetron sputtering to construct Ag-C-fiber nanostructures. The morphology of Ag-C-fiber nanostructures could be tuned through systematic variation of experimental parameters. In addition, the high absorptivity of C-fiber fabric will bring analyte enrichment effect in SERS measurement. The schematic diagram of the Ag-C-fiber preparation process is exhibited in Figure 1. Importantly, the $\mathrm{Ag}_{25}$-C-fiber (the sputtering time was $25 \mathrm{~min}$ ) exhibited excellent SERS performance with EEF higher than $3.871 \times 10^{6}$ and the LOD for crystal violet CV was as low as $1 \times 10^{-13} \mathrm{M}$. Moreover, the antiepileptic drugs (levetiracetam and sodium valproate) were investigated by $\mathrm{Ag}_{25}$-C-fiber SERS substrate. Overall, it is anticipated that the developed $\mathrm{Ag}_{25}-\mathrm{C}$-fiber SERS substrate could become an ideal SERS platform candidate in SERS-based biomedical sensing applications.

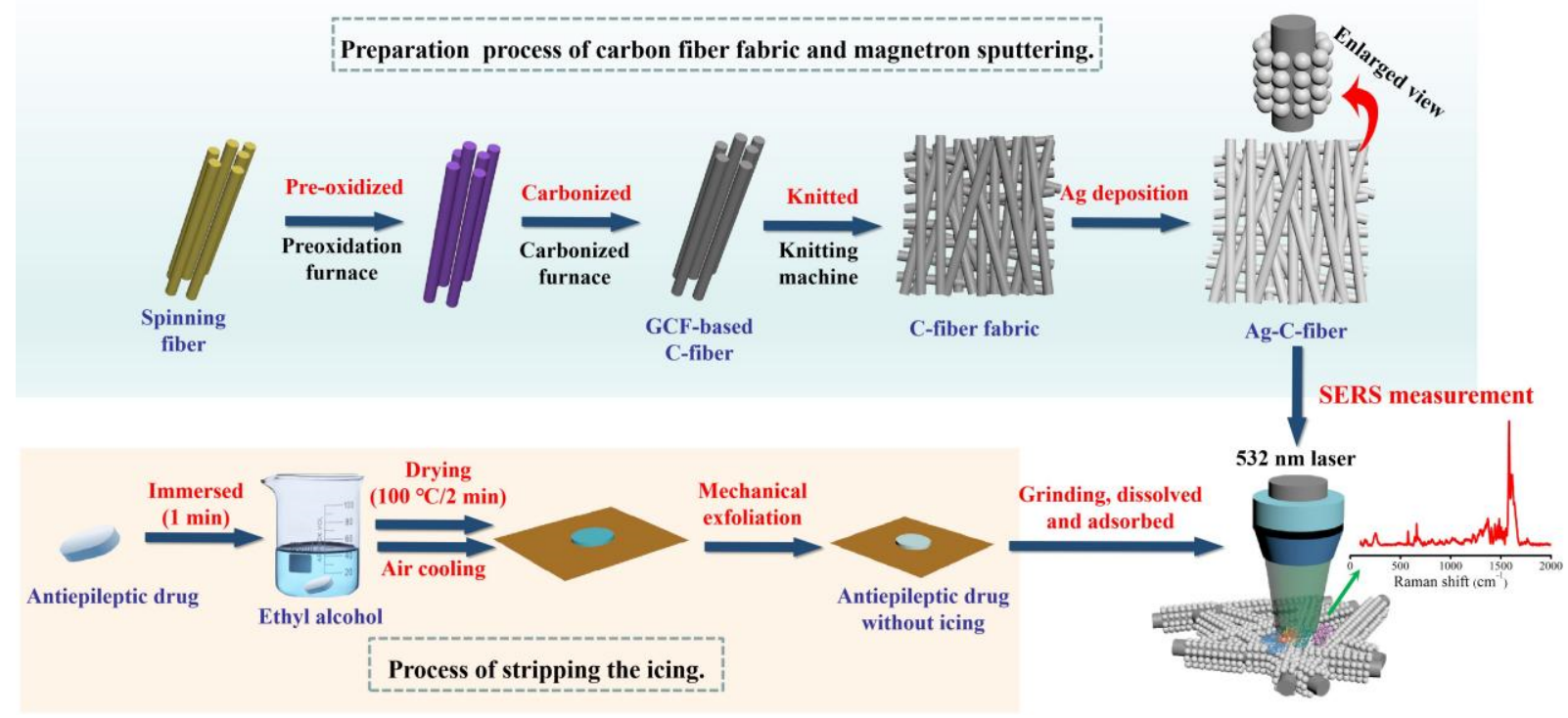

Figure 1. Illustration of fabrication of Ag-C-fiber and used for antiepileptic drug sensing by SERS.

\section{Experimental}

\subsection{Chemicals and Materials}

The Ag target (diameter: $60.0 \mathrm{~mm}$, thickness: $2.0 \mathrm{~mm}$, purity: 99.99\%) was obtained from Nanchang Hanchen New Materials Technology Co., Ltd., Nanchang, China. Rhodamine B (R6G) (Analytical Reagent, CAS Number: 81-88-9) and CV (Analytical Reagent, CAS Number: 603-47-4) were all obtained from J\&K Scientific Ltd., Beijing, China. Levetiracetam (CAS number: 102767-28-2) was purchased from Zhejiang Jingxin Pharmaceutical Co., Ltd., Shaoxing, China. Sodium valproate (CAS number: 1069-66-5) was obtained from Hunan Xiangzhong Pharmaceutical Co., Ltd., Shaoyang, China. Deionized water $(18.25 \mathrm{M} \Omega$ ) was used to prepare the solutions throughout the experiment.

\subsection{Process of Stripping the Icing from the Tablet}

Sodium valproate and levetiracetam need to strip the icing before being combined into probe molecular solutions. First, the icing tablets were placed in a beaker of anhydrous ethanol and soaked for $1 \mathrm{~min}$. After removing from the anhydrous ethanol, the treated tablets were placed in a drying oven at $100{ }^{\circ} \mathrm{C}$ for $2 \mathrm{~min}$. Next, they were taken out of the drying oven and cooled at room temperature. The icing layer can then be easily removed with a blade to obtain a very complete and smooth plain tablet. Finally, the sample with corresponding mass was dissolved in deionized water to prepare the solution with the desired concentration by means of the dilution method with a factor of 10 . R6G and CV solutions with different concentrations also followed the above solution dilution method. 


\subsection{Preparation of C-Fibers}

The prepared fibers were pre-oxidized in fluid air. The oxidized fibers were then carbonized under nitrogen atmosphere in a furnace. Last, in order to facilitate the preparation of SERS templates, they were spun into C-fiber fabric using a knitting machine.

\subsection{Preparation of Ag-C-Fiber Nanoarray}

The Ag-C-fiber nanoarray was prepared by high vacuum magnetron sputtering and an ion beam composite thin film deposition system (FJL560, Shenyang Scientific Instruments Co., Ltd., Shenyang, China). First, the Ag target was fixed on the sputtering target. There was a $3 \mathrm{~mm}$ gap between the shielding case and the Ag target to avoid a short circuit. The C-fiber fabric was then fixed on the sample table in the sputtering chamber. Before sputtering, in order to obtain high-purity Ag nanofilms, plasma cleaning was carried out in the sputtering chamber with $5 \mathrm{sccm}$ argon flow for $10 \mathrm{~min}$. Next, the molecular pump was turned on, and after about $20 \mathrm{~min}$, the pressure in the sputtering chamber reached $3.5 \times 10^{-3} \mathrm{~Pa}$. At this time, the flow display was opened and the value of MFC2 to 30 was adjusted. The sputtering power was controlled at $14 \mathrm{~W}$. In this case, the sputtering chamber successfully lit up and magnetron sputtering coating began. By controlling the magnetron sputtering time, we obtained a series of SERS substrates with different morphologies. If the magnetron sputtering time was $x$ min, the SERS substrate was named $\mathrm{Ag}_{\mathrm{x}}-\mathrm{C}$-fiber.

\subsection{Characterization}

Field emission scanning electron microscopy (FE-SEM) (SU8220, Hitachi, Tokyo, Japan) was utilized to characterize the morphology of C-fiber and $\mathrm{Ag}_{\mathrm{x}}-\mathrm{C}$-fiber with an acceleration voltage of $10.0 \mathrm{kV}$. SERS spectra were recorded by a confocal micro-Raman spectrometer (Horiba LabRAM HR800, HORIBA Jobin Yvon, Paris, France) with excitation laser wavelength of $532 \mathrm{~nm}$. During the SERS measurement, the acquisition time of each Raman spectrum was $10 \mathrm{~s}$ and the laser power was set at $0.1 \mathrm{~W}$. In the data processing, the original SERS spectrum was further processed to remove excess noise.

\section{Results and Discussion}

\subsection{Morphology Characterization of the C-Fiber Fabric}

Figure 2a shows the FE-SEM image of the unmodified C-fiber fabric. It can be seen that the C-fiber surface was clean. The C-fiber fabric was a 3D structure and arranged in a crisscross pattern. This nanostructure provided a multistage mechanism to ensure stronger Raman signal enhancement. The unmodified C-fiber showed a circular cross-section without cracks, as shown in Figure $2 b$, the diameter of the carbon fiber was $19 \pm 1 \mu \mathrm{m}$. This large specific surface area of C-fiber fabric was an ideal material for the preparation of SERS active substrate.
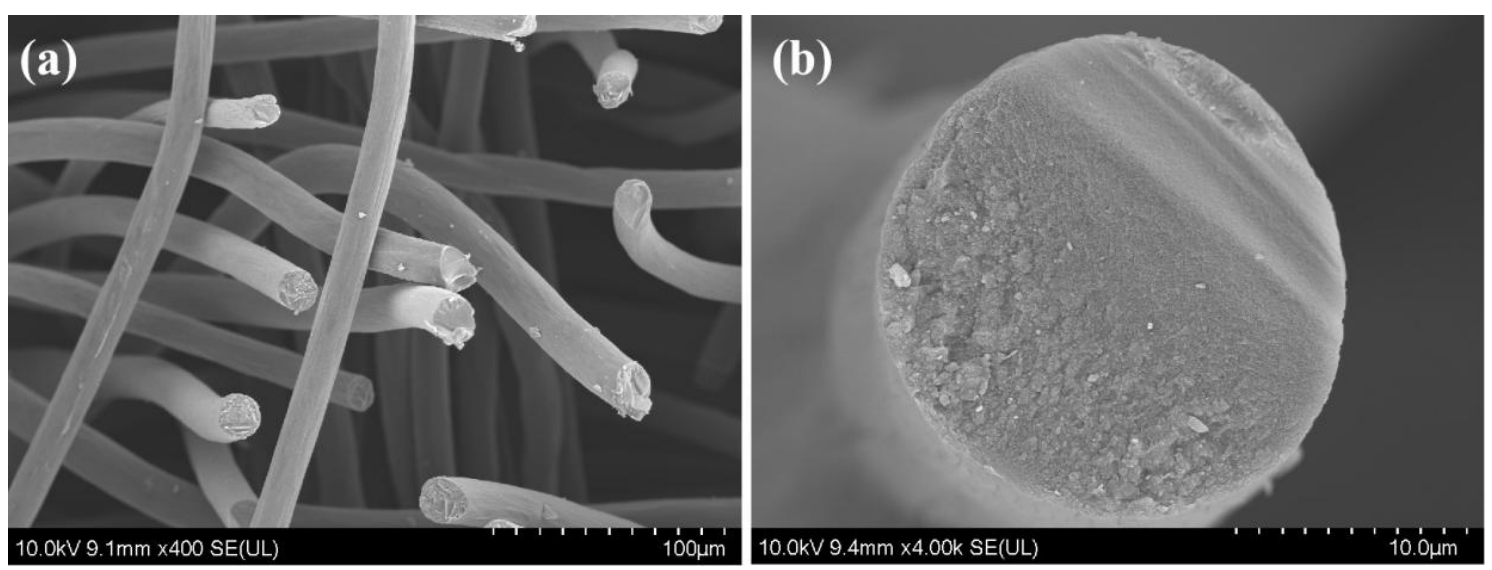

Figure 2. FE-SEM images of (a) the prepared C-fiber fabric and (b) the cross-section of C-fiber. 


\subsection{Morphology Characterization of the $A g_{x}$-C-Fiber}

In the field of SERS technology detection, the morphology characteristics of noble metal nanostructure can directly affect the quality of Raman spectrum, thus it plays a decisive role in the detection of samples [30]. In this work, magnetron sputtering technology [31], which was widely used in material synthesis, was used to modify the Ag nanoislands onto the $\mathrm{C}$-fiber fabric template to fabricate $\mathrm{Ag}_{\mathrm{x}}-\mathrm{C}$-fiber nanostructure. Figure 3 shows the FE-SEM images of $\mathrm{Ag}_{\mathrm{x}}-\mathrm{C}$-fiber with low magnification. The nanoisland-like $\mathrm{Ag}$ nanostructure synthesized in Figure 3 had unique morphology and rough surface, which made it a suitable active substrate for SERS detection.
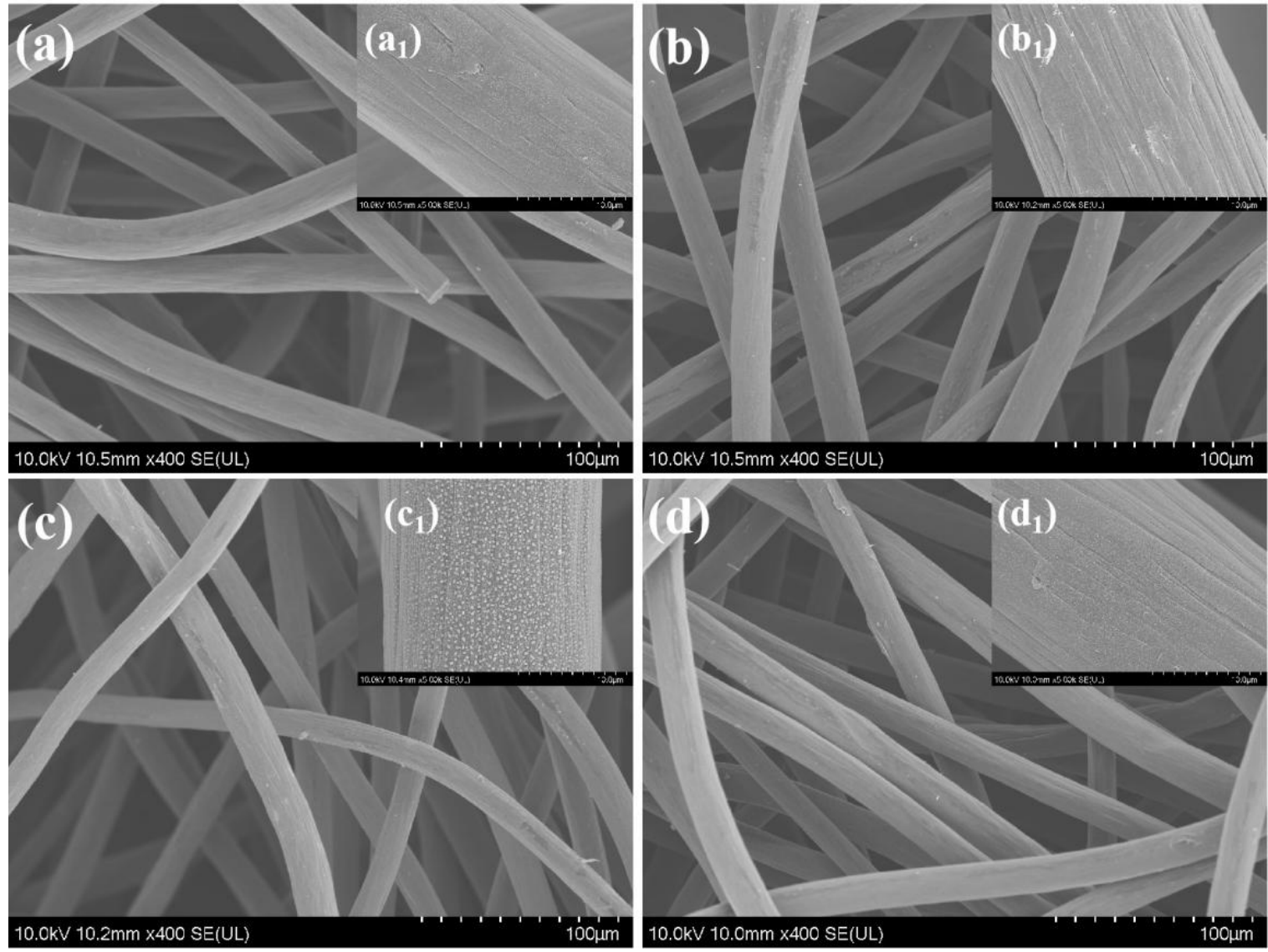

Figure 3. FE-SEM images of $\mathrm{Ag}_{\mathrm{x}}-\mathrm{C}$-fiber substrates prepared with different sputtering time: (a) $\mathrm{Ag}_{15}$-C-fiber substrate; (b) $\mathrm{Ag}_{20}$-C-fiber substrate; (c) $\mathrm{Ag}_{25}$-C-fiber substrate and (d) $\mathrm{Ag}_{30}$-C-fiber substrate. $\left(\mathbf{a}_{\mathbf{1}}-\mathbf{d}_{\mathbf{1}}\right)$ The corresponding amplifying FE-SEM images of (a-d).

The surface morphology of nanoisland-like Ag nanostructures on the smooth C-fiber fabric was well-dispersed as shown in the amplifying FE-SEM images in Figure 4. When the sputtering time was set at $15 \mathrm{~min}$, the average size of the Ag nanoislands was located at $30 \pm 2 \mathrm{~nm}$ as shown in Figure $4 \mathrm{a}$ and the illustration. Figure $4 \mathrm{~b}$ indicated that the longer the sputtering time, the denser the Ag deposition, the larger the size of the Ag nanoislands. The illustration in Figure $4 \mathrm{~b}$ also exhibited that the average size of the Ag nanoislands was $50 \pm 2 \mathrm{~nm}$. As the sputtering time reached $25 \mathrm{~min}$, both the size of the Ag nanoislands and the surface roughness were all significantly enhanced. As we can see from the size distribution diagram in Figure 4c, the average size of the larger Ag nanoislands was $80 \pm 2 \mathrm{~nm}$, and the average size of these smaller ones was 20-50 nm, respectively. This hierarchical Ag nanoisland structure provided more potential multi-level "hot spots" regions in which the significant local electromagnetic field enhancement was formed. On the other hand, as Figure 4c displayed that the Ag nanoislands consisted of sharp spikes and rough surfaces, which can also act as an amplifier of the electromagnetic 
field when interacting with incident light to generate local surface plasmonic waves and thus intensifying Raman signals. With further extension of the sputtering time to $30 \mathrm{~min}$, the multi-level Ag nanoisland-like nanostructure faded away and the nanostructures were evolved into densely distributed Ag nanoaggregates. Figure 5a,b exhibited the side-view FE-SEM images of $\mathrm{Ag}_{25}$-C-fiber substrate; interestingly, the side of the $\mathrm{Ag}_{25}-\mathrm{C}$-fiber fabric also exhibited thick Ag nanoisland-like arrays.
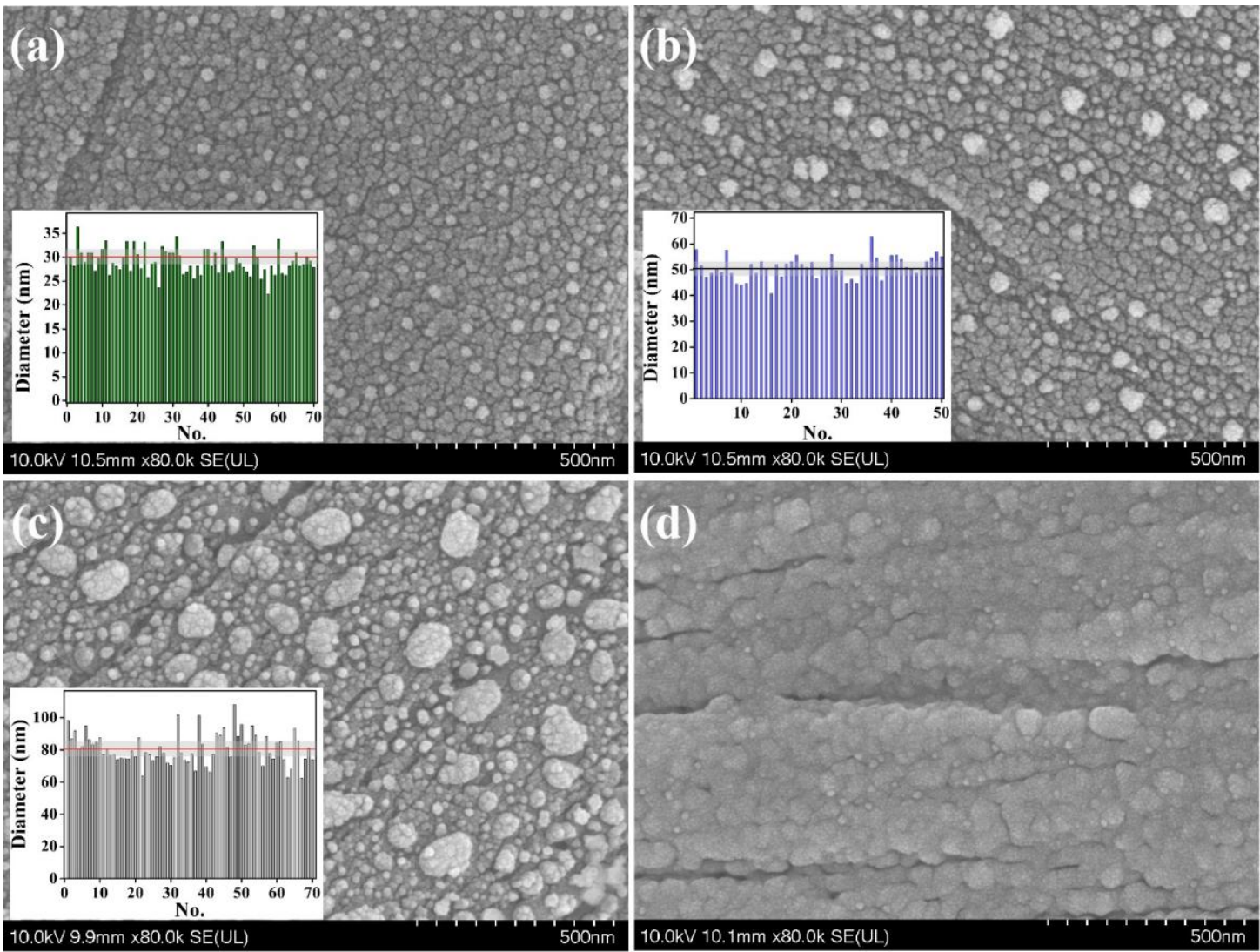

Figure 4. Amplifying FE-SEM images of $\mathrm{Ag}_{\mathrm{x}}-\mathrm{C}$-fiber substrates prepared with different sputtering times: (a) $\mathrm{Ag}_{15}$-C-fiber substrate; (b) $\mathrm{Ag}_{20}$-C-fiber substrate; (c) $\mathrm{Ag}_{25}-\mathrm{C}$-fiber substrate and (d) $\mathrm{Ag}_{30}-$ $\mathrm{C}$-fiber substrate. The illustrations were the histograms of size distribution in the corresponding FE-SEM images.
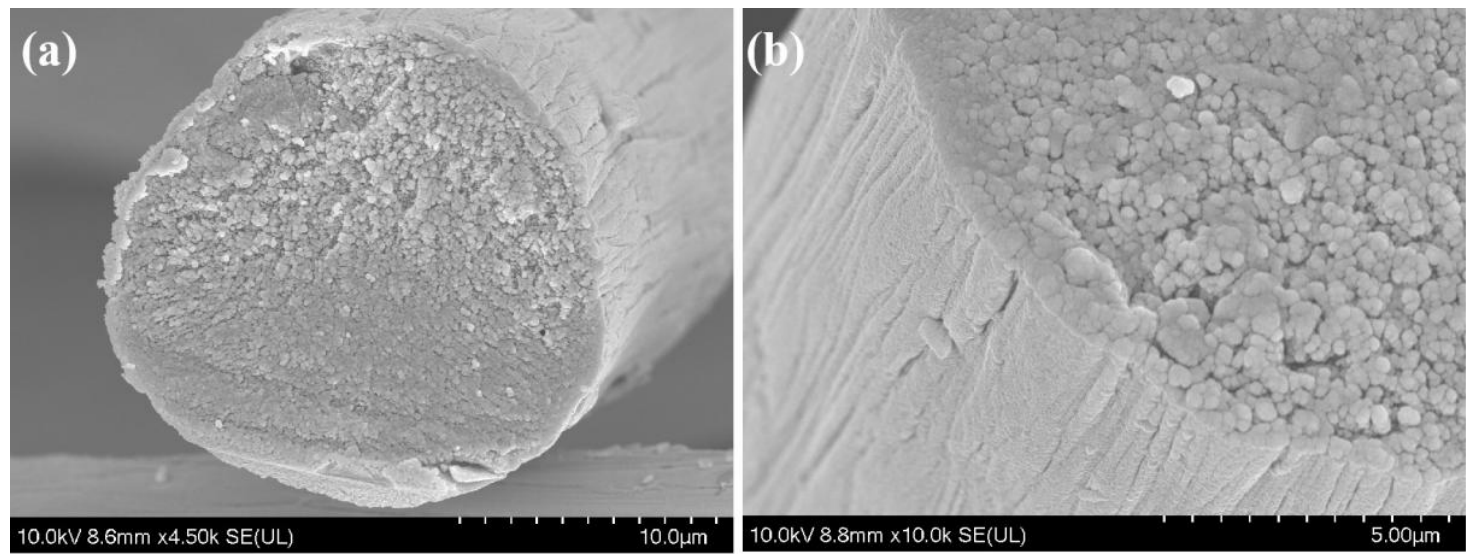

Figure 5. (a,b) Amplifying FE-SEM images of $\mathrm{Ag}_{25}$-C-fiber substrate from side view. 


\subsection{Effect of Sputtering Time on SERS Performance}

In order to explore the potential advantages of assembled nanostructures in electromagnetic signal amplification, we investigated the Raman signal enhancement ability of different $\mathrm{Ag}_{\mathrm{x}}-\mathrm{C}$-fiber substrates in detecting a kind of dye molecule called R6G with the concentration of $10^{-6} \mathrm{M}$. Thanks to well-established vibrational features, R6G was always employed as a probe molecule to evaluate the SERS performance. Figure $6 \mathrm{a}_{1}$ shows the Raman spectrum of R6G powder, and all the typical characteristic peaks, such as 612,775 , 1361,1510 and $1650 \mathrm{~cm}^{-1}$, can be observed and the band assignments were listed in Table 1 according to Schatz et al. [32]. Figure $6 \mathrm{a}_{2}$ shows the Raman spectrum of neat $\mathrm{C}$-fiber. Two characteristic peaks located at $1350 \mathrm{~cm}^{-1}$ and $1600 \mathrm{~cm}^{-1}$ which belonged to the breathing mode of point ( $D$ band) and the graphitic hexagon-pinch mode ( $G$ band) were observed. This phenomenon indicated that C-fiber was a good indicator of Raman signal.
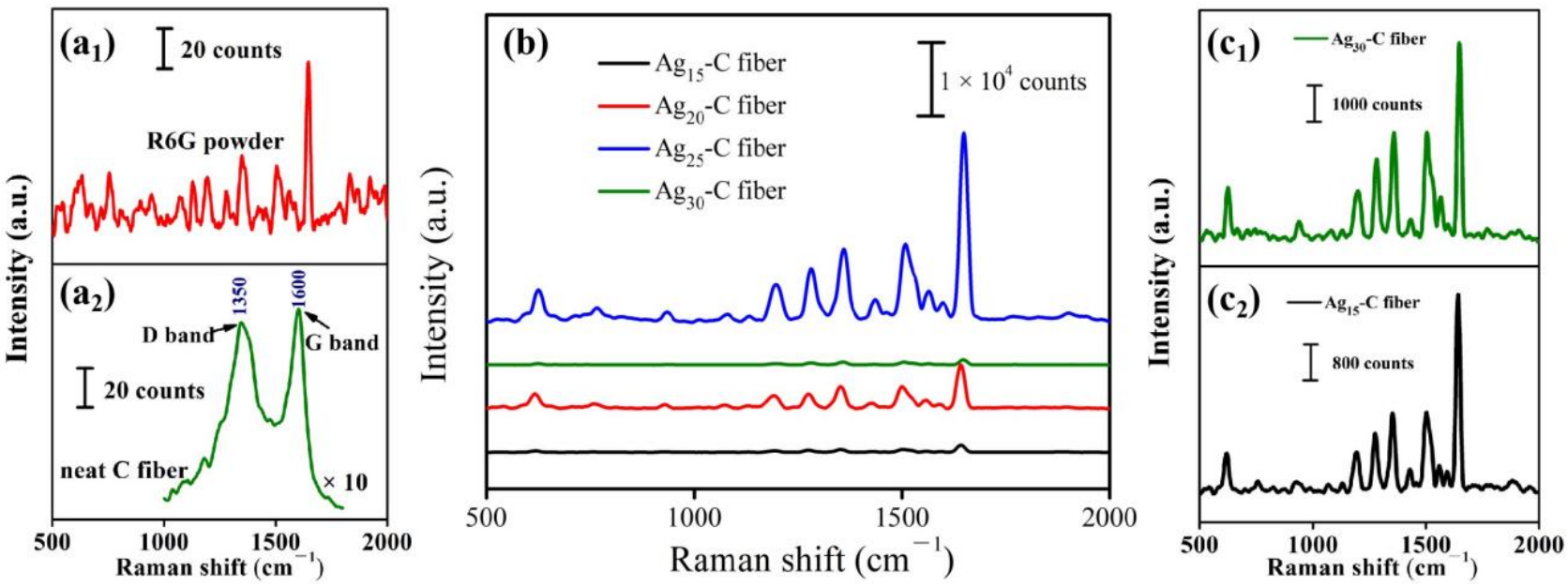

Figure 6. $\left(\mathbf{a}_{1}, \mathbf{a}_{2}\right)$ Raman spectra of R6G powder and neat $C$ fiber; (b) Raman spectra of $10^{-6}$ M R6G on different $\mathrm{Ag}_{\mathrm{x}}-\mathrm{C}$-fiber substrates; $\left(\mathbf{c}_{1}, \mathrm{c}_{2}\right)$ the Raman spectra of $10^{-6} \mathrm{M}$ R6G on $\mathrm{Ag}_{30}-\mathrm{C}$-fiber and $\mathrm{Ag}_{15}$-C-fiber substrates consistent with Figure $6 \mathrm{~b}$.

Table 1. Band assignments of Raman characteristic peaks of R6G.

\begin{tabular}{|c|c|c|}
\hline $\begin{array}{c}\text { Neat R6G } \\
\text { Powder }\left(\mathrm{cm}^{-1}\right)\end{array}$ & $\begin{array}{c}\text { SERS } \\
\text { Experimental Data }\left(\mathrm{cm}^{-1}\right)\end{array}$ & Vibrational Mode \\
\hline 612 & 611 & In plane $\mathrm{C}-\mathrm{C}-\mathrm{C}$ bending \\
\hline 775 & 773 & Out of plane $\mathrm{C}-\mathrm{H}$ bending \\
\hline 1184 & 1185 & $\begin{array}{l}\text { In plane xanthenes ring deformation, } \mathrm{C}-\mathrm{H} \\
\text { bending, N-H bending }\end{array}$ \\
\hline 1361 & 1360 & $\begin{array}{l}\text { Xanthenes ring stretching, in plane C-H } \\
\text { bending }\end{array}$ \\
\hline 1510 & 1509 & $\begin{array}{l}\text { Xanthenes ring stretching, } \mathrm{C}-\mathrm{N} \text { stretching, } \\
\mathrm{C}-\mathrm{H} \text { bending, } \mathrm{N}-\mathrm{H} \text { bending }\end{array}$ \\
\hline 1650 & 1648 & $\begin{array}{c}\text { Xanthenes ring stretching, in plane } \mathrm{C}-\mathrm{H} \\
\text { bending }\end{array}$ \\
\hline
\end{tabular}

Many previous reports have proven that when the plasmonic nanostructures with different morphologies interacted with incident light, there were great differences in electromagnetic enhancement performance. Therefore, we employed R6G as the probe molecule to evaluate the SERS performance of $\mathrm{Ag}_{\mathrm{x}}-\mathrm{C}$-fiber substrates. Figure $6 \mathrm{~b}$ shows the Raman spectra of $10^{-6}$ M R6G obtained from $\mathrm{Ag}_{\mathrm{x}}-\mathrm{C}$-fiber substrates. Figure $6 \mathrm{c}_{1}, \mathrm{c}_{2}$ is the amplifying Raman spectra of $10^{-6} \mathrm{M}$ R6G on $\mathrm{Ag}_{30}-\mathrm{C}$-fiber and $\mathrm{Ag}_{15}$-C-fiber substrates, consistent with Figure $6 \mathrm{~b}$. The location of characteristic peaks from the SERS experimental data 
are summarized in Table 1 . We can conclude that when the sputtering time ranged from 15 to $25 \mathrm{~min}$, the Raman signal intensity of $10^{-6} \mathrm{M}$ R6G increased with the increase of sputtering time, when the sputtering time reached $25 \mathrm{~min}$, the $10^{-6} \mathrm{M}$ R6G functionalized $\mathrm{Ag}_{25}$-C-fiber substrate exhibited the strongest Raman signal enhancement performance. Figures $4 c$ and $5 b$ can also prove this point. With the increase of sputtering time, the nanogaps became smaller and the surface roughness of Ag nanoislands increased. Large areas of Ag nanoislands were close to each other, providing a large range of effective and dense Raman signal enhancement "hot spots" for electromagnetic field amplification. On the other hand, the high density and multi-level "hot spots" generated between (or on the surface) Ag nanoislands with different sizes also guaranteed the best Raman signal enhancement effect of $\mathrm{Ag}_{25}-\mathrm{C}$-fiber substrate. When the sputtering time increased to $30 \mathrm{~min}$, the conversion efficiency of the electromagnetic enhanced "hot spots" was reduced due to the clustering of irregular Ag nanoislands. Therefore, in the following work, we selected the $\mathrm{Ag}_{25}$-C-fiber substrate with the best Raman signal enhancement effect to evaluate other SERS performances.

\subsection{Polarization Property Study of the $\mathrm{Ag}_{25}$-C-Fiber Substrate}

Method of Raman scattering spectroscopy can be performed in a wide range of experimental setups, which mainly depend on the appropriate choice of wavelength and polarization direction. Especially, the change of polarization direction of incident light can cause a series of spectral phenomena [33]. For example, the confusion of laser polarization may lead to very strong Raman spectra showing rather weak Raman spectra. Therefore, in the field of SERS detection, we should be aware of this phenomenon when explaining the experimental results. In this study, the polarization performance of $\mathrm{Ag}_{25}-\mathrm{C}$-fiber substrate was firstly investigated. Figure 7 a shows the principle diagram of polarization measurement of $\mathrm{Ag}_{25}-\mathrm{C}$-fiber substrate modulated by rotating half-wave plate. By adjusting the polarization direction, a series of Raman spectra at different polarization angles $(\theta)$ were obtained, and the correlation of substrate polarization was discussed, as shown in Figure $7 b$. Figure $7 \mathrm{~b}$ describes the Raman spectra of $\mathrm{CV}$ absorbed on $\mathrm{Ag}_{25}-\mathrm{C}$-fiber substrate at different polarization angles under $532 \mathrm{~nm}$ incident light. Obviously, when the incident light incidented on the "hot spots" area at different polarization angles, the intensity of Raman signal was significantly different. Figure 7c-e shows the Raman signal intensity distribution at 1172, 1370 and $1587 \mathrm{~cm}^{-1}$ characteristic peaks on the $\mathrm{Ag}_{25}-\mathrm{C}$-fiber substrates under different polarization angles. It can be concluded that the Raman signal intensities changed with the ranging of the polarization angles. Particularly, all the characteristic peaks observed maximum Raman signal enhancement when the polarization angle was located at $0^{\circ}$. Therefore, in the next SERS measurement, all the polarization directions of incident light followed the above law.

\subsection{Sensitivity of $\mathrm{Ag}_{25}-\mathrm{C}$-Fiber Substrate}

Benefiting from the great quantity of multi-level "hot spots" generated on the $\mathrm{Ag}_{25}-\mathrm{C}$ fiber substrate and the efficient SERS response of $\mathrm{Ag}_{25}-\mathrm{C}$-fiber nanostructures to aromatic molecules such as R6G and $\mathrm{CV}$, the $\mathrm{Ag}_{25}-\mathrm{C}$-fiber substrate exhibited high-efficiency trace detection capability for $\mathrm{CV}$ molecule with different concentrations. Figure $8 \mathrm{a}$ shows the Raman spectra of CV with different concentrations varying from $1 \times 10^{-7}$ to $1 \times 10^{-13} \mathrm{M}$ absorbed on $\mathrm{Ag}_{25}-\mathrm{C}$-fiber substrates. It can be found that the intensities of Raman signal decreased with the decrease of $\mathrm{CV}$ concentrations. When the CV concentration decreased to $1 \times 10^{-13} \mathrm{M}$, as shown in Figure 8 b, the Raman characteristic peaks located at 913, $1172,1370,1587$ and $1620 \mathrm{~cm}^{-1}$ could still be distinctly identified, which demonstrated that the LOD for $\mathrm{CV}$ functionalized $\mathrm{Ag}_{25}$-C-fiber substrate was established at $1 \times 10^{-13} \mathrm{M}$. The ultra-high sensitivity of $\mathrm{Ag}_{25}-\mathrm{C}$-fiber substrate can be comparable to the current international advanced LOD detection level, as listed in Table 2. The high sensitivity of the $\mathrm{Ag}_{25}$-C-fiber substrate can be attributed to three factors. First, $\mathrm{C}$-fibers were woven into $\mathrm{C}$-fiber fabric so that the substrate has good absorbability. When the $10 \mu \mathrm{L}$ probe 
molecule solution was dropped on the $\mathrm{Ag}_{25}$-C-fiber substrate, the probe molecules were easily enriched in the "hot spots" regions, thus increasing the sensitivity. Second, the large specific surface area of the $\mathrm{Ag}_{25}$-C-fiber substrate provided more potential sites for "hot spots", which further improved the electromagnetic field enhancement performance of the $\mathrm{Ag}_{25}$-C-fiber substrate and gave it have ultra-high sensitivity. Last, the CM provided by carbon-based materials can also increase the sensitivity of the $\mathrm{Ag}_{25}-\mathrm{C}$-fiber substrate.
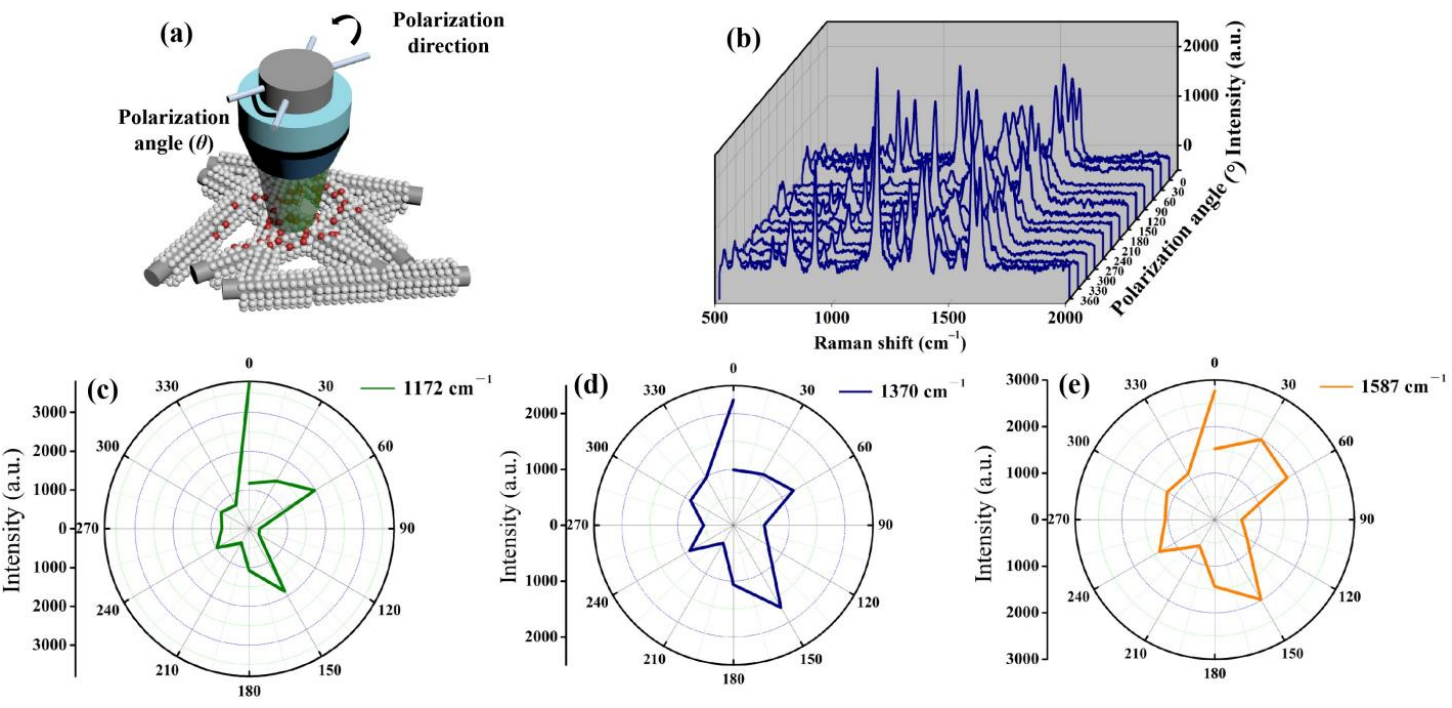

Figure 7. (a) The principle diagram of polarization measurement of $\mathrm{Ag}_{25}$-C-fiber SERS substrate; (b) SERS spectra of $\mathrm{CV}$ at different polarization angles on the $\mathrm{Ag}_{25}-\mathrm{C}$-fiber substrate; (c-e) polar curves of the Raman intensities at 1172, 1370 and $1587 \mathrm{~cm}^{-1}$ characteristic peaks.
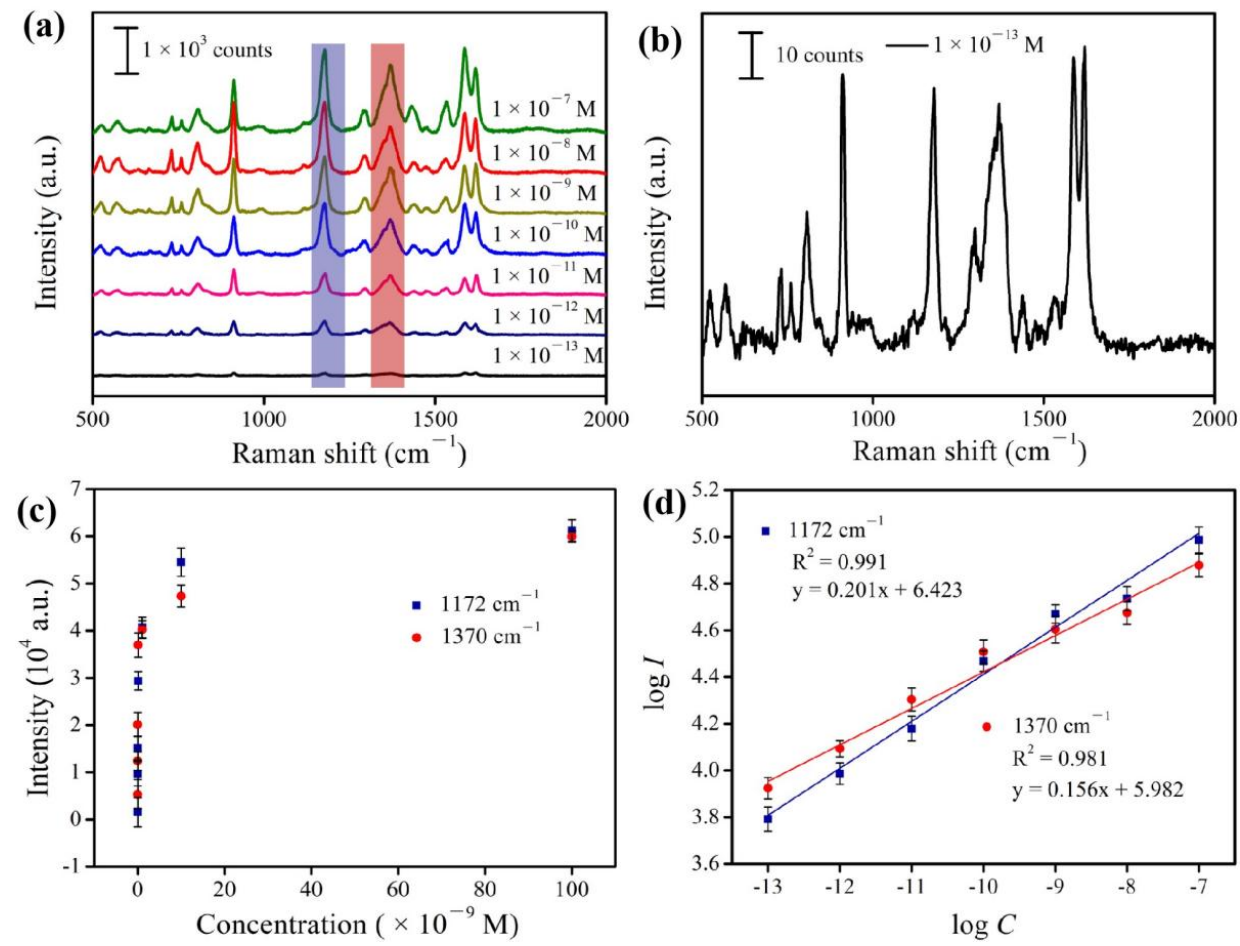

Figure 8. (a) Raman spectra of CV solution with different concentrations on $\mathrm{Ag}_{25}$-C-fiber substrate; (b) Raman spectra of $10^{-13} \mathrm{M} \mathrm{CV}$ absorbed on $\mathrm{Ag}_{25}$-C-fiber substrate; (c) Raman signal intensities at main peaks of $\mathrm{CV}$ at different concentrations; (d) linear calibration plots between the Raman signal intensity and CV concentration. 
Table 2. LOD for CV on different SERS substrates with different nanostructures reported previously.

\begin{tabular}{cccc}
\hline Nanostructure & Probe Molecule & LOD (M) & Reference \\
\hline $\mathrm{S}-\mathrm{MOF} @ \mathrm{Au}$ & $\mathrm{CV}$ & $5 \times 10^{-12}$ & Wang et al. [34] \\
$\mathrm{Ag} @ \mathrm{Fe}_{2} \mathrm{O}_{3}$ & $\mathrm{CV}$ & $1.7 \times 10^{-9}$ & Xu et al. [35] \\
Copper nanocorns & $\mathrm{CV}$ & $1 \times 10^{-13}$ & Xu et al. [36] \\
$\mathrm{TiO}_{2}-\mathrm{Ag}-\mathrm{GO}$ & $\mathrm{CV}$ & $1 \times 10^{-9}$ & Zhang et al. [37] \\
$\mathrm{Ag} / \mathrm{AgBr} / \mathrm{ZnO}$ & $\mathrm{CV}$ & $1 \times 10^{-12}$ & Zhang et al. [38] \\
$\mathrm{Ag} @ \mathrm{Cu} @ \mathrm{Cicada}$ wing & $\mathrm{CV}$ & $1 \times 10^{-10}$ & Yan et al. [39] \\
$\mathrm{Ag}_{25}-\mathrm{C}-$-fiber & $\mathrm{CV}$ & $1 \times 10^{-13}$ & This work \\
\hline
\end{tabular}

S, self-supporting; MOF, metal organic framework; GO, graphene oxide.

Figure 8c displayed the relationship between the Raman signal integrated intensities and the concentrations of CV. It can observed that when choosing the characteristic peaks of 1172 and $1370 \mathrm{~cm}^{-1}$, the responses between the logarithmic Raman signal integrated intensity $(\log I)$ and the logarithmic concentration $(\log C)$ were nearly linear, as shown in Figure $8 d$. The correlation coefficients $\left(R^{2}=0.991,0.981\right)$ indicated that this novel $\mathrm{Ag}_{25}$ C-fiber substrate can provide the feasibility to quantitative detection of $\mathrm{CV}$ solution at unknown concentration even of the other aromatic molecules.

\subsection{Reproducibility of $\mathrm{Ag}_{25}-\mathrm{C}$-Fiber Substrate}

For a standard SERS detection system, one of the key detection criteria is the reproducibility of Raman signal when the probe molecules are absorbed on the noble metal SERS substrate. In many cases, the uneven distribution or absence of "hot spots" will lead to a great deviation in Raman signal intensity, which will affect the statistical results of Raman signal detection.

In order to further test the Raman signal reproducibility of $\mathrm{Ag}_{25}$-C-fiber substrate, the Raman spectra obtained from $\mathrm{Ag}_{25}$-C-fiber substrates were carried out by employing $10^{-10} \mathrm{M} \mathrm{CV}$ as probe molecule. Figure 9a displayed the 10 Raman spectra of $10^{-10} \mathrm{M} \mathrm{CV}$ randomly recorded from $10 \mathrm{Ag}_{25}-\mathrm{C}$-fiber substrate, the intensity of all scattering peaks hardly changed. All scattering peaks overlapped well, with neither red shift nor blue shift. Normally, the RSD value was used to quantitatively characterize the reproducibility of an SERS detection system. It is widely accepted that when the RSD value was less than $20 \%$, the Raman signal reproducibility of the SERS system was outstanding [40]. Figure 9b-d shows the Raman signal histograms at the characteristic peaks of 913, 1179 and $1370 \mathrm{~cm}^{-1}$, respectively. The RSD values of these three characteristic peaks were less than $12.97 \%$, which proved that the Raman signal on $\mathrm{Ag}_{25}-\mathrm{C}$-fiber substrate exhibited good reproducibility and can be used for actual sample detection. The good reproducibility of Raman signal also further indicated that the constructed $\mathrm{Ag}_{25}$-C-fiber SERS platform had strong accuracy and credibility in the future application of clinical drug detection.

\subsection{Electromagnetic Field Simulation and EF Calculation}

Three-dimensional finite-difference time-domain (3D-FDTD) method is one of the most widely used analytical methods in dealing with the interaction between electromagnetic fields and scatterers of arbitrary shapes [41]. The main idea is to directly reflect the timedomain characteristics of electromagnetic fields by solving the finite difference equation under appropriate initial and boundary conditions, and use clear and vivid images to describe complex physical processes [42]. In this paper, the 3D-FDTD method was used to simulate the interaction between $\mathrm{Ag}_{25}$-C-fiber model and electromagnetic field. Meanwhile, the parameters of Ag materials in this paper referred to Gai's theoretical research on the modified Drude model of wide wave bands [43]. Figure 10a shows the 3D-FDTD model of $\mathrm{Ag}_{25}-\mathrm{C}$-fiber substrate, and Figure 10b,c displayed the spatial distributions of electromagnetic field intensity of $\mathrm{Ag}_{25}-\mathrm{C}$-fiber model in $\mathrm{x}-\mathrm{y}$ plane and $\mathrm{x}-\mathrm{z}$ plane, respectively. Strong and multi-level electromagnetic enhancement "hot spots" were generated at the nanogaps of different sizes of Ag nanoislands. Electromagnetic field simulation results 
showed that the maximum value of electromagnetic field intensity in $\mathrm{Ag}_{25}$-C-fiber model was $25.9 \mathrm{~V} / \mathrm{m}$. In this case, the theoretical enhancement factor (TEF) of $\mathrm{Ag}_{25}-\mathrm{C}$-fiber model was $4.50 \times 10^{6}[44]$.
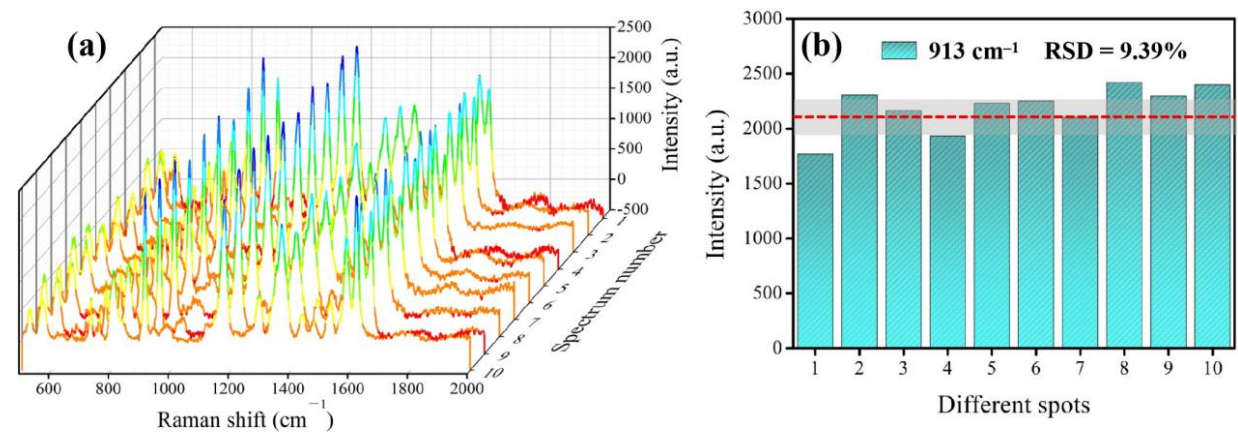

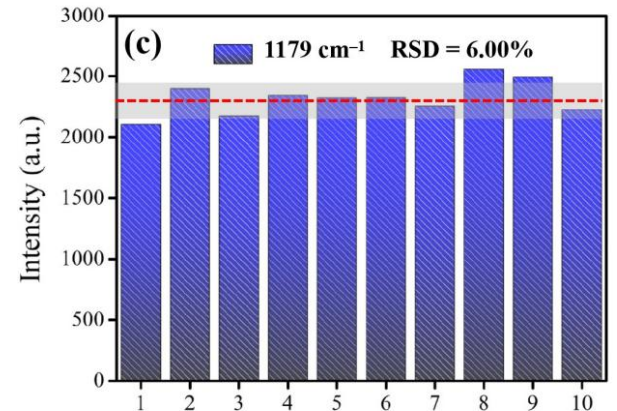

Different spots

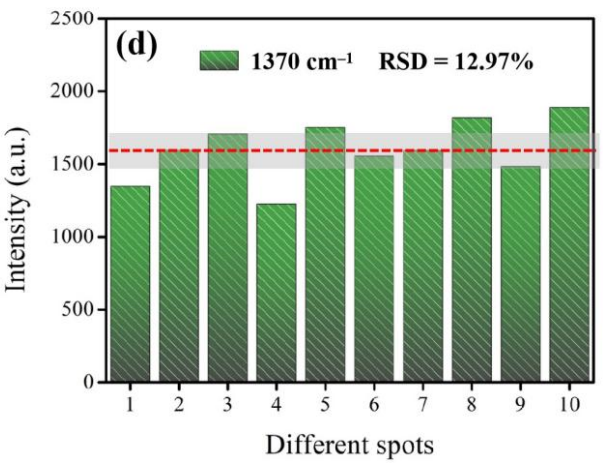

Figure 9. (a) Raman spectra of $10^{-10} \mathrm{M} \mathrm{CV}$ solution collected from 10 randomly selected substrates; (b-d) the Raman signal histograms at the characteristic peaks of 913, 1179 and $1370 \mathrm{~cm}^{-1}$ and the corresponding RSD values.
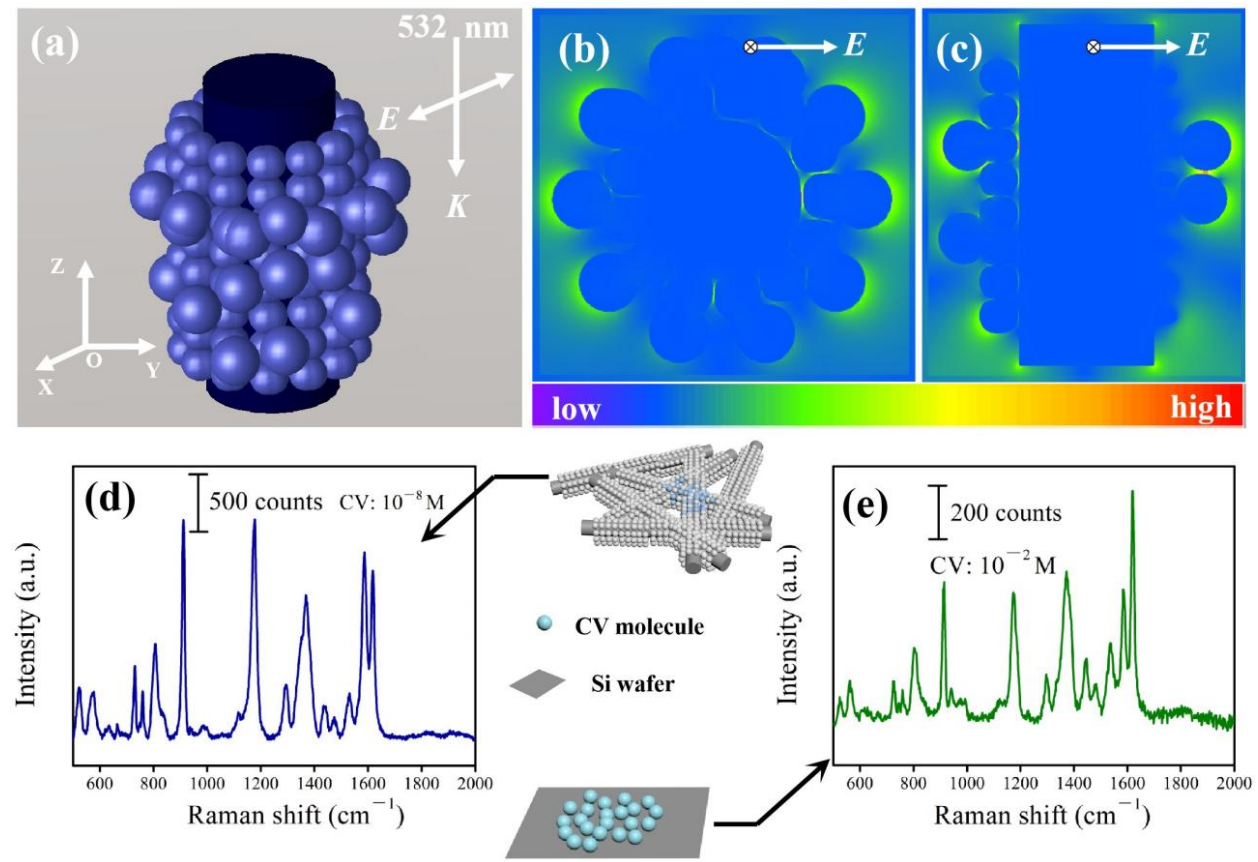

Figure 10. (a) 3D-FDTD model of $\mathrm{Ag}_{25}$-C-fiber substrate; (b,c) spatial distributions of electromagnetic field intensity of $\mathrm{Ag}_{25}-\mathrm{C}$-fiber model in $\mathrm{x}-\mathrm{y}$ plane and $\mathrm{x}-\mathrm{z}$ plane; (d) Raman spectrum of $10^{-8} \mathrm{M} \mathrm{CV}$ solution on $\mathrm{Ag}_{25}$-C-fiber substrate; (e) Raman spectrum of $10^{-2} \mathrm{M} \mathrm{CV}$ solution on Si wafer. 
In order to further evaluate the Raman signal enhancement performance of the $\mathrm{Ag}_{25^{-}}$ C-fiber substrate from the perspective of experimental detection, the experimental enhancement factor (EEF) value was calculated according to Equation (1) [45]:

$$
\mathrm{EEF}=\frac{I_{\text {SERS }}}{I_{\text {Raman }}} \times \frac{N_{\text {Raman }}}{N_{\text {SERS }}}
$$

where $I_{S E R S}$ and $I_{\text {Raman }}$ are integrated Raman signal intensities of $10^{-8} \mathrm{M} \mathrm{CV}$ solution on $\mathrm{Ag}_{25}$-C-fiber substrate and normal Raman signal intensities of $10^{-2} \mathrm{M} \mathrm{CV}$ on Si wafer, $N_{\text {Raman }}$ and $N_{S E R S}$ represent the number of CV molecules on the Si wafer and $\mathrm{Ag}_{25}-\mathrm{C}$-fiber substrate, as shown in Figure 10d-e. The characteristic peak located at $1370 \mathrm{~cm}^{-1}$ was chosen to calculate the $I_{S E R S}$ and $I_{\text {Raman }}$. By calculating the integral areas of the characteristic peak of $1370 \mathrm{~cm}^{-1}$, the ratio of $I_{S E R S} / I_{\text {Raman }}$ was estimated to be 2.581 . The number of $\mathrm{CV}$ probe molecules ( $N$ : $N_{\text {Raman }}$ and $\left.N_{S E R S}\right)$ was defined by Equation (2) [46]:

$$
N=\left(\frac{N_{A} \times M \times V_{\text {solution }}}{S_{\text {sub }}}\right) \times S_{\text {laser }}
$$

where $N_{A}$ is the Avogadro constant, $M$ is the molar concentration of the CV probe molecule solution, $V_{\text {solution }}$ represents the volume of the $10 \mu \mathrm{L} \mathrm{CV}$ solution, $S_{\text {laser }}$ is the laser spot area and $S_{s u b}$ is the area of the CV solution absorbed on a different substrate. In the experiment, when $10 \mu \mathrm{L} \mathrm{CV}$ solution was dropped on the substrate, after drying, the adsorption area of $\mathrm{Ag}_{25}$-C-fiber substrate was 1.5 times larger than that on the Si wafer. During the SERS measurement, the diameter of the laser spot was $1 \mu \mathrm{m}$, therefore, the $S_{\text {laser }}$ was calculated to be $0.785 \mu \mathrm{m}^{2}$. In summary, the EEF value of $\mathrm{Ag}_{25}-\mathrm{C}$-fiber substrate at the $1370 \mathrm{~cm}^{-1}$ peak was $3.871 \times 10^{6}$.

The TEF value was less than the EEF value. This difference may be caused by two factors. Firstly, the Ag nanoisland in the simulation model was spherical and had a smooth surface. In fact, it can be seen from Figure $4 \mathrm{c}$ that the micro-nano structure of the actual Ag nanoisland scatterer was more complex, therefore, the electromagnetic field enhancement effect at the tip of the nanostructure was not fully reflected in the simulation model. Secondly, during the experimental detection, the CM mechanism superimposed the EEF through the dynamic charge transfer effect between the Ag nanoislands and CV probe molecules. However, the CM mechanism was ignored in 3D-FDTD simulation. We believed that the above two reasons were the main factors for the difference between TEF and EEF.

\subsection{Detection of the Antiepileptic Drugs by the $A g_{25}$-C-Fiber Substrate}

From the above discussion, we knew that there were a large number of multi-level "hot spots" on the surface of the $\mathrm{Ag}_{25}$-C-fiber substrate, which ensures the generation of local SPR effect. In addition, the ultra-high sensitivity and the outstanding Raman signal reproducibility of $\mathrm{Ag}_{25}-\mathrm{C}$-fiber substrate met the requirements of the standardized SERS detection system, therefore, the $\mathrm{Ag}_{25}$-C-fiber substrate was employed to detected two kinds of antiepileptic drugs called sodium valproate and levetiracetam.

Sodium valproate has antagonism effect on convulsion caused by various methods. It is effective for all types of human epilepsy, such as small seizure, myoclonic epilepsy, local seizure, major seizure and mixed epilepsy. Common adverse reactions include diarrhea, dyspepsia, nausea, vomiting, gastrointestinal spasm and menstrual cycle changes. Long-term use may cause pancreatitis and acute liver necrosis [47]. Its mechanism has not been fully clarified. Experiments show that this product can increase the synthesis of $\gamma$-aminobutyric acid (GABA) and reduce the degradation of GABA, so as to increase the inhibitory neurotransmitter GABA concentration, then reduce the excitability of neurons and inhibit seizures. In electrophysiological experiments, it was found that sodium valproate could produce $\mathrm{Na}^{+}$channel inhibition, which is similar to phenytoin, and it can damage the liver. 
Therefore, in order for ultra-sensitive detection of sodium valproate and further revealing the practicality of the $\mathrm{Ag}_{25}$-C-fiber substrate, a low-cost spectral detection method based on $\mathrm{Ag}_{25}-\mathrm{C}$-fiber SERS substrate was carried out. Figure 11a shows the Raman spectra of sodium valproate with different concentrations ranged from 1 to $10^{3} \mathrm{ng} / \mu \mathrm{L}$, the characteristic peaks centered at $1350 \mathrm{~cm}^{-1}$ and $1600 \mathrm{~cm}^{-1}$ can be clearly observed. The LOD for sodium valproate was $1 \mathrm{ng} / \mu \mathrm{L}$ which was far lower than that detected by reversed-phase HPLC method [48]. Meanwhile, under logarithmic operation, the linear modified relationship curves of Raman signal intensity to sodium valproate concentration at $1350 \mathrm{~cm}^{-1}$ and $1600 \mathrm{~cm}^{-1}$ are displayed in Figure $11 \mathrm{a}_{1}$, which provides a reference for the detection of sodium valproate solution with unknown concentration. On the other hand, these two characteristic peaks which belong to C-fiber can be considered as good candidates for label-free and nondestructive identification of the unknown molecules, concurrently contributing to improving the sensitivity of $\mathrm{Ag}_{25}$-C-fiber substrate.
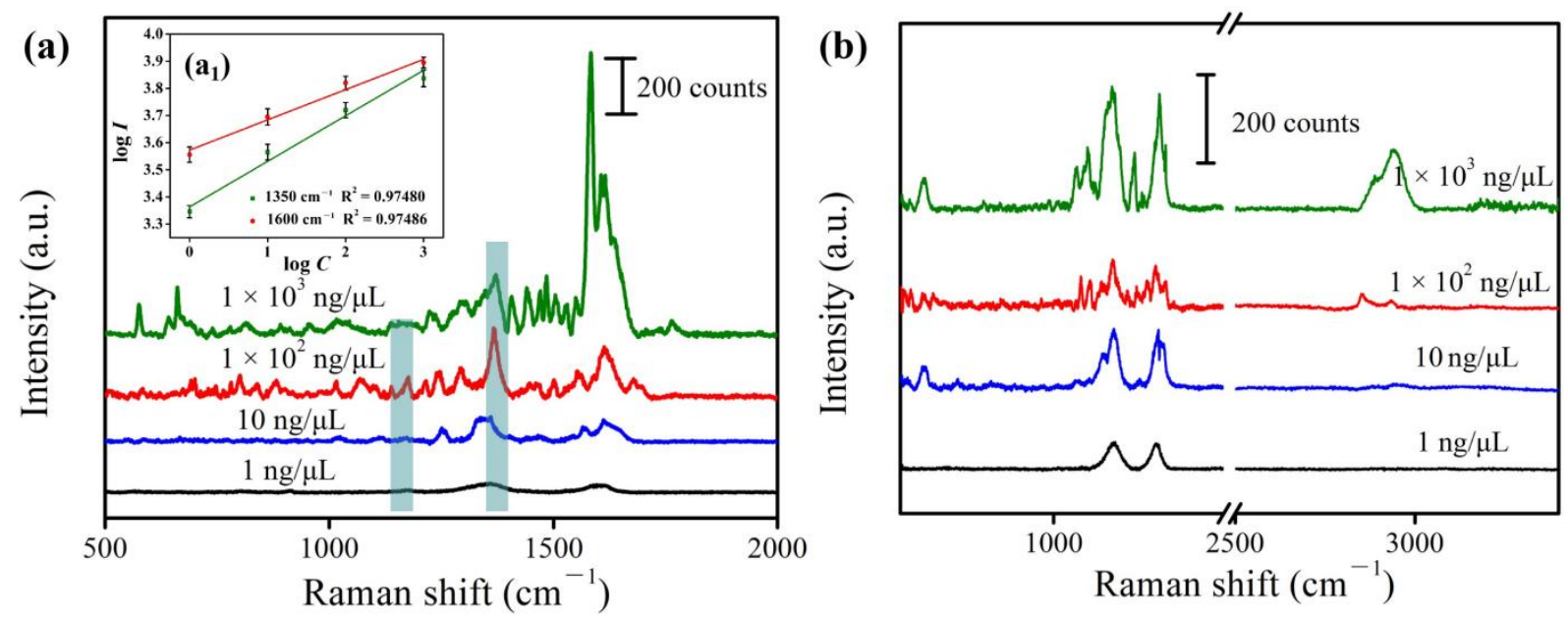

Figure 11. (a) Raman spectra of sodium valproate with different concentrations; $\left(\mathbf{a}_{1}\right)$ the linear modified relationship curves of Raman signal intensity to sodium valproate concentration at $1350 \mathrm{~cm}^{-1}$ and $1600 \mathrm{~cm}^{-1}$; (b) Raman spectra of levetiracetam with different concentrations.

Levetiracetam, another drug used in adults and children over 4 years of age with epilepsy, was successfully detected by using Raman scattering spectroscopy. As an antiepileptic drug, excessive dosage of levetiracetam may cause drowsiness, agitation, aggression, decreased level of consciousness, respiratory depression and coma and other clinical adverse reactions [49]. The results of levetiracetam Ames test, Chinese hamster ovary cells/hypoxanthine-guanine phosphoribosyl transferase locus mammalian cell gene mutation test, Chinese hamster ovary cell chromosome aberration test and mouse micronucleus test were all negative. Ames test and mouse lymphoma test of levetiracetam hydrolysate and main metabolite were negative. Figure $11 \mathrm{~b}$ shows the Raman spectra of levetiracetam with different concentrations which were successfully obtained by $\mathrm{Ag}_{25}$ C-fiber substrate. The LOD for levetiracetam was $1 \mathrm{ng} / \mu \mathrm{L}$, which was far lower than that of another work [50]. These results indicated that $\mathrm{Ag}_{25}-\mathrm{C}$-fiber substrate had a great application prospect in the field of ultra-sensitive detection of antiepileptic drugs and was worth promoting.

Meanwhile, cancer is one of the major diseases threatening human health and an important challenge facing mankind. The application of functional nanomaterials and related systems in cancer treatment is a research hot spot, mainly involving drug delivery systems, vaccines, diagnosis and imaging. SERS detection platforms constructed by nanotechnology can also potentially be used in cancer diagnosis, significantly enhancing the sensitivity of diagnosis, and providing the possibility for early detection and timely treatment of cancer $[51,52]$. Therefore, the $\mathrm{Ag}_{25}$-C-fiber SERS substrate has a strong application prospect in the field of tumor cell recognition and detection. 


\title{
4. Conclusions
}

We developed a controllable strategy to fabricate a $\mathrm{Ag}_{25}$-C-fiber SERS detection platform for efficient sensing sodium valproate and levetiracetam. This SERS-based substrate was fabricated by magnetron sputtering technology, by which dense Ag nanoislands with different sizes were immobilized onto the C-fiber, guaranteeing the ultra-high sensitivity and excellent reproducibility. In addition, the Ag nanoislands with different morphologies generated multi-level electromagnetic enhancement "hot spots", thus displaying excellent Raman signal enhanced performance with an EEF value calculated to be $3.871 \times 10^{6}$, which was consistent with the electromagnetic field intensity spatial distribution results achieved by 3D-FDTD method. More significantly, when used as an SERS sensor for antiepileptic drug detection, sodium valproate and levetiracetam can be successfully detected at an ultra-low concentration of $1 \mathrm{ng} / \mu \mathrm{L}$ in neutral $\mathrm{pH}$ solution. In the future, we will continue to modify the $\mathrm{Ag}_{25}-\mathrm{C}$-fiber SERS substrate with noble metal nanoparticles for the highly sensitive detection of active ingredients of traditional Chinese medicine, antibiotics and so on.

\begin{abstract}
Author Contributions: Conceptualization, K.L. and L.W.; data curation, J.G. (Jungai Gu); formal analysis, G.S. and W.Y.; funding acquisition, G.S.; investigation, G.S., W.H. and J.G. (Jianjun Gu); methodology, L.W. and K.L.; project administration, G.S. and K.L.; resources, X.H., L.W., W.H. and J.G. (Jianjun $\mathrm{Gu}$ ); software, X.H., J.G. (Jungai Gu) and W.Y.; supervision, G.S., L.W. and K.L.; validation, G.S. and X.H.; visualization, X.H. and J.G. (Jungai Gu); writing-original draft preparation, G.S., X.H. and W.Y.; writing-review and editing, G.S., K.L. and L.W. All authors have read and agreed to the published version of the manuscript.
\end{abstract}

Funding: This work was funded by the Science and Technology Project of Hebei Education Department (QN2021236) and the "Technology Innovation Guidance Project-Science and Technology Work Conference" of the Hebei Provincial Department of Science and Technology.

Institutional Review Board Statement: Not applicable.

Informed Consent Statement: Not applicable.

Data Availability Statement: Data sharing is not applicable to this article.

Acknowledgments: Authors would like to cordially thank Mingli Wang (Yanshan University) for his fruitful discussion and relevant commentary.

Conflicts of Interest: The authors declare no conflict of interest.

\section{References}

1. Ru, E.C.L.; Etchegoin, P.G. Single-molecule surface-enhanced Raman spectroscopy. Annu. Rev. Phys. Chem. 2012, 63, 65-87.

2. Wen, S.S.; Ma, X.W.; Liu, H.; Chen, G.; Wang, H.; Deng, G.Q.; Zhang, Y.T.; Song, W.; Zhao, B.; Ozaki, Y. Accurate monitoring platform for the surface catalysis of nanozyme validated by surface-enhanced Raman-kinetics model. Anal. Chem. 2020, 92, 11763-11770. [CrossRef] [PubMed]

3. Pan, X.; Li, L.; Lin, H.; Tan, J.; Li, M. A graphene oxide-gold nanostar hybrid based-paper biosensor for label-free SERS detection of serum bilirubin for diagnosis of jaundice. Biosens. Bioelectron. 2019, 145, 111713-111722. [CrossRef] [PubMed]

4. Zhang, C.; Wang, K.; Han, D.; Pang, Q. Surface enhanced Raman scattering (SERS) spectra of trinitrotoluene in silver colloids prepared by microwave heating method. Spectrochim. Acta A 2013, 122, 387-391. [CrossRef] [PubMed]

5. Yu, J.; Yang, M.; Li, Z.; Liu, C.; Wei, Y.; Zhang, C.; Man, B.; Lei, F. Hierarchical particle-in-quasicavity architecture for ultratrace in situ Raman sensing and its application in real-time monitoring of toxic pollutants. Anal. Chem. 2020, 92, 14754-14761. [CrossRef] [PubMed]

6. $\quad$ Cong, S.; Yuan, Y.; Chen, Z.; Hou, J.; Yang, M.; Su, Y.; Zhang, Y.; Li, L.; Li, Q.; Geng, F.; et al. Noble metal-comparable SERS enhancement from semiconducting metal oxides by making oxygen vacancies. Nat. Commun. 2015, 6, 7800-7806. [CrossRef] [PubMed]

7. Salomon, L.; Bassou, G.; Aourag, H.; Dufour, J.P.; de Fornel, F.; Carcenac, F.; Zayats, A.V. Local excitation of surface plasmon polaritons at discontinuities of a metal film: Theoretical analysis and optical near-field measurements. Phys. Rev. B 2002, 65, 125409. [CrossRef]

8. Willets, K.A.; Van Duyne, R.P. Localized surface plasmon resonance spectroscopy and sensing. Annu. Rev. Phys. Chem. 2007, 58, 267-297. [CrossRef]

9. Billmann, J.; Otto, A. Electronic surface state contribution to surface enhanced Raman scattering. Solid State Commun. 1982, 44, 105-107. [CrossRef] 
10. Otto, A.; Mrozek, I.; Grabhorn, H.; Akemann, W. Surface-enhanced Raman scattering. J. Phys. Condens. Matter 1992, 4, 1143-1212. [CrossRef]

11. Otto, A. The "chemical" (electronic) contribution to surface-enhanced Raman scattering. J. Raman Spectrosc. 2005, 36, 497-509. [CrossRef]

12. Wang, Y.X.; Liu, S.S.; Gao, W.T.; Zhang, Y.J.; Yang, J.H. Surface-enhanced Raman spectroscopy based on ordered nanocap arrays. Superlattice. Microst. 2012, 52, 750-758. [CrossRef]

13. Xu, W.G.; Mao, N.N.; Zhang, J. Graphene: A platform for surface-enhanced Raman spectroscopy. Small 2013, 9, 1206-1224. [CrossRef]

14. Shi, Q.; Gómez, D.E.; Dong, D.; Sikdar, D.; Fu, R.; Liu, Y.; Zhao, Y.; Smilgies, D.M.; Cheng, W. 2D freestanding janus gold nanocrystal superlattices. Adv. Mater. 2019, 31, 1900989. [CrossRef]

15. Wang, H.; Wu, Y.; Song, H. Synergistic effects of photonic crystal and gold nanostars for quantitative SERS detection of 3-Phenoxybenzoic acid. Appl. Surf. Sci. 2019, 476, 587-593. [CrossRef]

16. Li, X.X.; Lin, X.; Zhao, X.L.; Wang, H.Y.; Liu, Y.Y.; Lin, S.; Wang, L.; Cong, S.L. Self-assembled monolayer film of concave star-shaped Au nanocrystals as highly efficient SERS substrates. Appl. Surf. Sci. 2020, 518, 146217-146224. [CrossRef]

17. Nguyen, T.A.; Lee, S.W. Hierarchical Au nanostructure electrodeposited on graphene oxide-modified ITO glass as an ultrasensitive SERS substrate. Mater. Res. Bull. 2016, 83, 550-555. [CrossRef]

18. Zhao, L.; Gu, W.; Zhang, C.; Shi, X.; Xian, Y. In situ regulation nanoarchitecture of Au nanoparticles/reduced graphene oxide colloid for sensitive and selective SERS detection of lead ions. J. Colloid Interface Sci. 2015, 465, 279-285. [CrossRef] [PubMed]

19. Moon, Y.; Kumar, D.; Kim, H.; Sim, C.; Chang, J.H.; Kim, J.M.; Kim, H.; Lim, D.K. Amplified photoacoustic performance and enhanced photothermal stability of reduced graphene oxide coated gold nanorods for sensitive photoacoustic imaging. ACS Nano 2015, 9, 2711-2719. [CrossRef]

20. Gao, X.; Zhang, H.; Fan, X.Y.; Zhang, C.; Sun, Y.; Liu, C.D.; Li, Z.; Jiang, S.Z.; Man, B.Y.; Yang, C. Toward the highly sensitive SERS detection of bio-molecules: The formation of a 3D self-assembled structure with a uniform GO mesh between Ag nanoparticles and Au nanoparticles. Opt. Express 2019, 27, 25091-25106. [CrossRef]

21. Yang, W.; Li, Z.; Lu, Z.Y.; Yu, J.; Huo, Y.Y.; Man, B.Y.; Pan, J.; Si, H.P.; Jiang, S.Z.; Zhang, C. Graphene-Ag nanoparticles-cicada wings hybrid system for obvious SERS performance and DNA molecular detection. Opt. Express 2019, 27, 3000-3013. [CrossRef]

22. Lin, J.P.; Guan, G.Q.; Yang, W.Y.; Fu, H. The enhanced Raman scattering of Ag nanoparticles decorated on the carbon nanotube via a simple manipulation. Opt. Mater. 2019, 95, 109258-109263. [CrossRef]

23. Qin, X.J.; Si, Y.M.; Wang, D.W.; Wu, Z.Y.; Li, J.S.; Yin, Y.D. Nanoconjugates of Ag/Au/carbon nanotube for alkynemeditated ratiometric SERS imaging of hypoxia in hepatic ischemia. Anal. Chem. 2019, 91, 4529-4536. [CrossRef]

24. Wang, Q.; Hu, R.J.; Chen, M.M.; Zhang, J.X.; Chen, L.C.; Lin, Z.Y.; Dong, Y.Q.; Fu, F.F. Hybridizing carbon-based dot-capped manganese dioxide nanosheets and gold nanoparticles as a highly sensitive surface-enhanced Raman scattering substrate. Anal. Chem. 2021, 93, 9744-9751. [CrossRef] [PubMed]

25. Ghopry, S.A.; Sadeghi, S.M.; Farhat, Y.; Berrie, C.L.; Alamri, M.; Wu, J.Z. Intermixed WS $\mathrm{W}_{2}+\mathrm{MoS}_{2}$ nanodisks/graphene van der Waals heterostructures for surface-enhanced Raman spectroscopy sensing. ACS Appl. Nano Mater. 2021, 4, 2941-2951. [CrossRef]

26. Zhu, W.; Feng, X.Q.; Liu, Z.D.; Zhao, M.H.; He, P.; Yang, S.W.; Tang, S.W.; Chen, D.; Guo, Q.L.; Wang, G.; et al. Sensitive, reusable, surface-enhanced Raman scattering sensors constructed with a 3D graphene/Si hybrid. ACS Appl. Nano Mater. 2021, 19, 23081-23091. [CrossRef] [PubMed]

27. Liang, X.; Li, N.; Zhang, R.H.; Yin, P.G.; Zhang, C.M.; Yang, N.; Liang, K.; Kong, B. Carbon-based SERS biosensor: From substrate design to sensing and bioapplication. NPG Asia Mater. 2021, 13, 8-44. [CrossRef]

28. Zhang, P.; Liu, G.Q.; Guo, J.; Zhou, X.; Cai, W.P. Research progress of surface enhanced Raman scattering (SERS) properties for carbon based composite material. J. Funct. Mater. 2019, 6, 06001-06007.

29. Krivchenko, V.A.; Itkis, D.M.; Evlashin, S.A.; Semenenko, D.A.; Goodilin, E.A.; Rakhimov, A.T.; Stepanov, A.S.; Suetin, N.V.; Pilevsky, A.A.; Voronin, P.V. Carbon nanowalls decorated with silicon for lithiumion batteries. Carbon 2012, 50, $1438-1442$. [CrossRef]

30. Guo, L.T.; Cao, H.W.; Cao, L.P.; Li, N.; Zhang, A.Q.; Shang, Z.B.; Jiao, T.F.; Liu, H.L.; Wang, M.L. Improve optical properties by modifying Ag nanoparticles on a razor clam SERS substrate. Opt. Express 2021, 29, 5152-5165. [CrossRef] [PubMed]

31. Wang, M.L.; Shang, Z.B.; Yan, X.Y.; Shi, G.C.; Cao, H.W.; Ma, W.L.; Jiao, T.F. Enhance fluorescence study of grating structure based on three kinds of optical disks. Opt. Commun. 2021, 481, 126522-126530. [CrossRef]

32. Jensen, L.; Schatz, G.C. Resonance Raman scattering of rhodamine $6 \mathrm{G}$ as calculated using time-dependent density functional theory. J. Phys. Chem. A 2006, 110, 5973-5977. [CrossRef]

33. Šubr, M.; Procházka, M. Polarization- and angular-resolved optical response of molecules on anisotropic plasmonic nanostructures. Nanomaterials 2018, 8, 418. [CrossRef]

34. Wang, Q.Z.; Zhao, Y.J.; Bu, T.; Wang, X.; Xu, Z.H.; Hui, Z.S.; Wang, L. Semi-sacrificial template growth-assisted self-supporting MOF chip: A versatile and high-performance SERS sensor for food contaminants monitoring. Sens. Actuators B. Chem. 2022, 352 , 131025-131032. [CrossRef]

35. Xu, D.; Duan, L.F.; Jia, W.L.; Yang, G.H.; Gu, Y.Q. Fabrication of $\mathrm{Ag} @ \mathrm{Fe}_{2} \mathrm{O}_{3}$ hybrid materials as ultrasensitive SERS substrates for the detection of organic dyes and bilirubin in human blood. Microchem. J. 2021, 161, 105799105805. [CrossRef] 
36. Xu, D.P.; Zhang, Y.F.; Zhang, S.; Yang, W.; Chen, J. Ultrasensitive SERS detection of crystal violet and malachite green based on high surface roughness copper nanocorns prepared via solid-state ionics method. Sens. Actuators A Phys. 2021, 331, 113042-113048. [CrossRef]

37. Zhang, M.F.; Sun, H.R.; Chen, X.; Zhou, H.Y.; Xiong, L.Z.; Chen, W.; Chen, Z.H.; Bao, Z.Y.; Wu, Y.C. The influences of graphene oxide (GO) and plasmonic Ag nanoparticles modification on the SERS sensing performance of $\mathrm{TiO}_{2}$ nanosheet arrays. J. Alloys. Compd. 2021, 864, 158189-158198. [CrossRef]

38. Zhang, Z.Y.; Yu, J.J.; Ma, L.Y.; Sun, Y.S.; Wang, P.P.; Wang, T.H.; Peng, S. Preparation of the plasmonic Ag/AgBr/ZnO film substrate for reusable SERS detection: Implication to the Z-scheme photocatalytic mechanism. Spectrochim. Acta A Mol. Biomol. Spectrosc. 2020, 224, 117381. [CrossRef]

39. Yan, X.Y.; Wang, M.L.; Sun, X.; Wang, Y.H.; Shi, G.C.; Ma, W.L.; Hou, P. Sandwich-like Ag@Cu@CW SERS substrate with tunable nanogaps and component based on the Plasmonic nanonodule structures for sensitive detection crystal violet and 4-aminothiophenol. Appl. Surf. Sci. 2019, 479, 879-886. [CrossRef]

40. Natan, M.J. Concluding remarks: Surface enhanced Raman scattering. Faraday Discuss. 2006, 132, 321-328. [CrossRef]

41. Hao, Z.S.; Li, N.; Cao, H.J.; Guo, L.T.; Cao, H.W.; Li, N.; Cao, L.P.; Liu, H.L.; Jiao, T.F.; Wang, M.L. Modified Ag nanoparticles on the regular array structure to improve the optical properties. J. Lumin. 2022, 243, 118684-118694. [CrossRef]

42. Yee, K.S. Numerical solution of initial boundary value problems involving maxwell's equations in isotropic media. IEEE Trans. Antenn. Propag. 1966, 14, 302-307.

43. Gai, H.F.; Wang, J.; Tian, Q. Modified Debye model parameters of metals applicable for broadband calculations. Appl. Opt. 2007, 46, 2229-2233. [CrossRef]

44. García-Vidal, F.J.; Pendry, J.B. Collective theory for surface enhanced Raman scattering. Phys. Rev. Lett. 1996, 77, 1163-1166. [CrossRef] [PubMed]

45. Lv, M.Y.; Teng, H.Y.; Chen, Z.Y.; Zhao, Y.M.; Zhang, X.; Liu, L.; Wu, Z.L.; Liu, L.M.; Xu, H.J. Low-cost Au nanoparticle-decorated cicada wing as sensitive and recyclable substrates for surface enhanced Raman scattering. Sens. Actuators B Chem. 2015, 209, 820-827. [CrossRef]

46. Li, N.; Hao, Z.S.; Cao, H.J.; Guo, L.T.; Cao, H.W.; Li, N.; Yang, Y.F.; Jiao, T.F.; Liu, H.L.; Wang, M.L. Acupressure mat-like nanostructure with improved SERS performance. Opt. Laser Technol. 2022, 148, 107765-107773. [CrossRef]

47. Ardianto, C.; Wardani, H.A.; Nurrahmi, N.; Rahmadi, M.; Khotib, J. Alpha-lipoic acid ameliorates sodium valproate-induced liver injury in mice. Vet. World 2020, 13, 963-966. [CrossRef]

48. Elrefay, H.; Ismaiel, O.A.; Hassan, W.S.; Shalaby, A.; Fouad, A. RP-HPLC stability-indicating method for simultaneous determination of sodium valproate, methylparaben and propylparaben in oral solution. Acta Chromatogr. 2022, 34, 203-209. [CrossRef]

49. Ha, C.; Lee, H.S.; Joo, E.Y.; Shon, Y.M.; Hong, S.B.; Seo, D.W.; Lee, S.Y. Levetiracetam therapeutic drug monitoring in a large cohort of Korean epileptic patients. Pharmaceuticals 2021, 14, 826. [CrossRef]

50. Karaś-Ruszczyk, K.; Kuczyńska, J.; Sienkiewicz-Jarosz, H.; Kurkowska-Jastrzębska, I.; Bienkowski, P.; Restel, M.; Samochowiec, J.; Mierzejewski, P. Comparison of plasma, saliva, and hair levetiracetam concentrations. Ther. Drug Monit. 2017, 39, 263-268. [CrossRef]

51. Ahmadian, E.; Maleki, D.S.; Sharifi, S.; Shahi, S.; Khalilov, R.; Eftekhari, A.; Hasanzadeh, M. The potential of nanomaterials in theranostics of oral squamous cell carcinoma: Recent progress. Trac-Trend Anal. Chem. 2019, 116, 167-176. [CrossRef]

52. Ahmadian, E.; Samiei, M.; Hasanzadeh, A.; Kavetskyy, T.; Jafari, S.; Alipour, M.; Salatin, S.; Rameshrad, M.; Sharifi, S.; Eftekhari, A.; et al. Monitoring of drug resistance towards reducing the toxicity of pharmaceutical compounds: Past, present and future. J. Pharmaceut. Biomed. 2020, 186, 113265. [CrossRef] [PubMed] 